\title{
No more fear
}

Dental anxiety and phobias are no laughing matter. That's why EndoCare are committed to helping patients who experience these fears and try to overcome them, together.

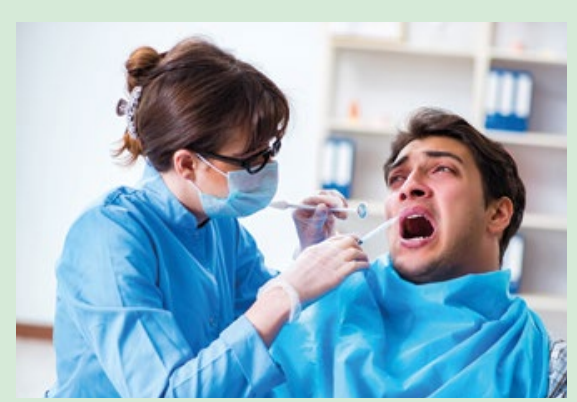

The highly skilled team of specialists are all experienced in providing the latest endodontic techniques to help ensure that treatment is as painless as possible.

Furthermore, they help patients feel relaxed and at ease with movies and music, ensuring their comfort before, during and after treatment with quality care every step of the way! They return your patients to you with highly detailed information about the treatment they have received, and the suggested next steps.

For further information please call EndoCare on 02072240999 or visit www.endocare.co.uk.

\section{Next-level intraoral scanning}
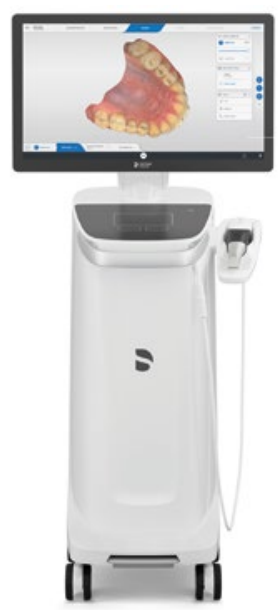

Taking digital impressions just got a whole lot faster, easier and more accurate with Dentsply Sirona's new Primescan available from Clark Dental.

Featuring Smart Pixel Sensor and dynamic depth scan technology, Primescan captures highly accurate, photorealistic images of the oral cavity with ease. Capable of scanning materials such as amalgam, gold and glass, it offers the facility to export STL and exocad files to your preferred laboratory.

Primescan can also be used to design restorations and produce sophisticated CEREC guides for dental implants. When combined with the latest CEREC milling units, Primescan supports a wide range of restorative procedures, from singletooth to full-arch cases.

For more information call Clark Dental on 01268733 146, email info@clarkdental.co.uk or visit www.clarkdental.co.uk.

\section{Free from contaminants}

Maintaining the high-quality performance of dental loupes includes ensuring that they are clean and free of contamination. Nuview makes it easier than ever for practitioners to achieve this with its dedicated Continu Cleaning and Disinfectant Wipes for Loupes.

These alcohol-free, pre-saturated wipes are excellent for efficient cleaning of dental loupes, and are proven extremely effective against a wide range of harmful bacteria, fungi, and viruses.

Available in a conveniently sized pack of 35 individual wipes, Continu Cleaning and Disinfectant Wipes ensure that dentists comply with HTM 01-05 requirements to regularly clean equipment that is close to patient areas. The use of these wipes also ensures loupes are free of contamination, without causing damage to the frames or lenses. Get in touch with Nuview for further details.

For more information call Nuview on 01453 872266, email info@nuview-ltd.com or visit www.nuview.co.uk.

\section{A real all-rounder}

W\&H is delighted to launch the new Proxeo AURA air polishing handpiece, which boasts an advanced powder jet system. Available with three different powders for a wide range of indications, the Proxeo AURA ensures efficient, atraumatic cleaning supra- and subgingivally. It is designed with a $360^{\circ}$ rotate function and an innovative adjustment ring, which enables you to switch between prophylaxis and periodontal treatment with ease.

Once connected to your existing hose, the Proxeo AURA can be combined with a variety of spray heads, including slender perio tips for cleaning hard-to-reach areas.

Highly ergonomic and easy to use, the Proxeo AURA is a real all-rounder for achieving optimal treatment results.

To find out more visit www.wh.com/ en_uk, call 01727874990 or email office. uk@wh.com.

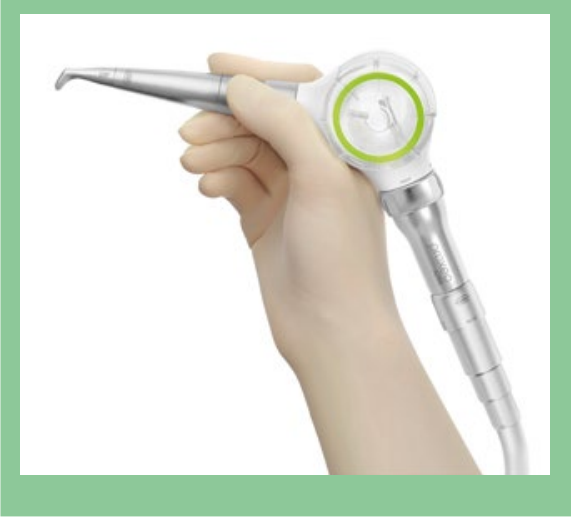

\section{Keep your patients protected}

Initial Medical's range of Steri-7 Xtra disinfectants is the ideal choice for professionals who want to ensure that hands and surfaces are pathogen free. The unique formula in these products deactivates $99.9999 \%$ of pathogens including high risk viruses such as HIV or Hepatitis C.

The products also have Reactive Barrier Technology, meaning they prevent pathogens from recolonising for up to 72 hours between applications.

Find out more by visiting www.initial. co.uk/medical or calling: 08708504045 . 